\title{
The Effect of Nano Technology on Architecture
}

\author{
Leena S. B. Yasin, and Diala I Atiyat
}

\begin{abstract}
Nowadays, in the $21^{\text {st }}$ century there is a great development in technical skills and construction, as well as new technological inventions, which evolved rapidly. The use of these advanced technology, have a significant impact on humans plans for the future and the way of thinking.

Nanotechnology has emerged as a result of the global international integration in the field of technology. This control of the level of small nanometers was the beginning of a revolution in contemporary technology in all aspects of life, especially the design of materials, construction methods, as well as thinking and architectural developments.

Recently a new discipline of architecture has been revealed by the revolution of nanotechnology. The discipline is Nano architecture, which uses the nano materials, products, telecommunication, or even Nano-shapes in the treatment of structure and construction.

This research sheds light on the impact of the advances of nanotechnology in modern architecture, both the architectural materials and construction, in the initial stages of architectural thinking and constructing. In order to reach to the extent of the impact of this progress on the Nano-architecture and through the study include:

And to clarify what this new intellectual trends have a great significant impact in reshaping and changing the architecture in the previous years, not only in the form of architecture, but in all aspects of the design, which led to the birth of the new architectural trends of technology and widely accepted.
\end{abstract}

Keywords - architecture, nanotechnology, nano architecture, nanomaterial introduction, trends.

\section{RESEARCH PROBLEM}

The Nanotechnology and its applications have been revealed in all the fields of life and science, especially after the scientific evolution of all intellectual and applied levels. The architecture field like all other fields share a great deal of progress, whether that progress on the new level of the structure of modern architecture, applications for new materials or change thinking and the architectural design.

This research is directed towards solving the problem on one hand the new technology prompting the architects to think in a new way for architecture, developments and formation, and on the other hand the emergence of new materials and applications, as well as the change in the style of structural systems for new sustainable buildings.

L. Y. Lecturer at Jordan University. The Kingdom of Jordan.

D. A. Lecturer at AL-Balqaa Applied University. Kingdom Of Jordan.

\section{THE IMPORTANCE OF RESEARCH}

The importance of research lies to shed light on the change in the architecture, as well as in building materials and the structure due to the effect by technological progress, especially the nanotechnology. This progress led to the emergence of a new mechanism in architectural thinking, building construction and materials and modern techniques, which changed the course of thought and architectural construction whether it's negative or positive change, as well as illustrate the architectural advantage of all aspects of nanotechnology and how to make Nano architecture Building sustainable.

\section{RESEARCH GOALS}

1. Identify the intellectual contemporary architectural trends and their impact on changing the architectural approach of the previous years, whether it's on the level of architectural thinking and design, materials, or the structure until arriving to the results of its effect through case studies.

2. Identify the concept of nanotechnology and its applications and, also the impact of it on the environment, and risks.

3. Identify the Nano architecture concept and its applications on two levels.

4. The effect from ideas and suggestions of the architects of studying previous case studies and practical applications.

5. Display international initiatives and the reflection of nanotechnology on the future of sustainable architecture, both negatively and positively.

6. The ability of this progress in the field of architecture, the application of an old architectural ideas into the present age using nanotechnology with the presentation of some of these ideas, and the possibility of their application.

7. The side effects and the negative to the progress of nanotechnology in architecture and all the fields of thinking and design and establish a system materials.

\section{RESEARCH Methodology}

The research will based upon the descriptive and analytical approaches in gathering data.

\section{INTRODUCTION}

Nanotechnology is a great scientific development, which promises "more for less ". It is also offers ways to create smaller, cheaper, lighter, faster, and stronger devices and materials. This technology has a great role in reducing energy and use less raw materials. 
There are many examples of nanotechnology applications, from the simple to the complex. The simple application such as reducing the need for harmful cleaning agents. The complex applications such as the mobile phone, which has been developed dramatically in a few years to be smaller, faster, and cleverer.

The applications of Nanotechnology are in all aspects of our life. Lately it had been witnessed in medicine, industry, communications, transportation, and ore important in Architecture. The use of nanotechnology in architecture is wide and varies, from the early stages of construction to the finishing touches, especially in the choosing the right materials. The nanotechnology offers a new way of thinking for the architects according to the various option of it.

\section{NANOTECHNOLOGY}

\section{A. Nanotechnology Definition}

The term "nanotechnology" is often used as an all-encompassing term for science, engineering, and technology conducted at the Nano scale level- which involves the understanding and control of matter at dimensions between approximately 1 to 100 nanometers $(\mathrm{nm})$. For reference, a single nanometer is one of millionth of millimeter. It would take roughly 50,000 nanometers to span the diameter of an average human hair. (Source: Nanotechnology and the Built Environment)

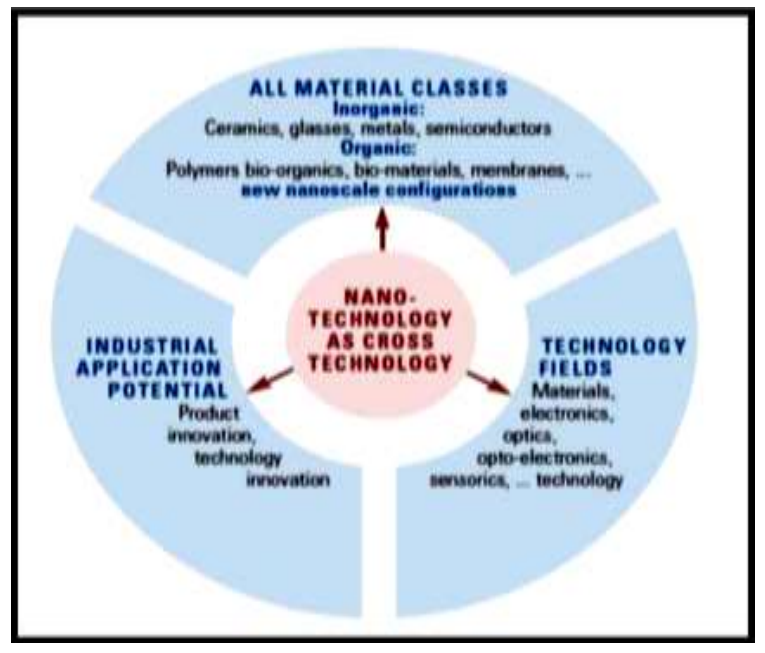

Fig. 1. Nanotechnology as transsectoral technology influences all important materials classes and technology fields, providing both product and technology, Reference: (http://en.wikipedia.org/wiki/Green_technologies).

\section{A. Approaches}

\section{Top-down Approach}

Nanostructures can be made by two complementary approaches. With top-down technology nanostructures and devices are made through scaling and miniaturization. It requires precision engineering down to the nano-scale, usually by lithographic patterning, embossing or imprint techniques with subsequent etching and coating steps. Some Examples are: Nanoelectronics, Nano fibers and Nanoclay.( National Nanotechnology Initiative - Strategic Plan 2004).

B. Bottom-up Approach

The other complementary route is bottom-up, constructing nanostructures through atom-by-atom or molecule-bymolecule engineering. It usually requires wet-chemical or vapor-phase processing routes such as atomic layer deposition. In some cases atomic or molecular manipulation is applied via optical, electrical or mechanical nanoprobes. Some examples are: Carbon nanotubes, Nanowires, Quantum dots and Nanomedicine. (National Nanotechnology Initiative Strategic Plan 2004).

\section{B. Applications \\ - Nanoparticles \\ - Carbon Nanotubes \\ - Quantum Dots \\ - Nanowires \\ - Buckyballs.}

\section{Nano architecture}

Refers to the use of Nanotechnology + Architecture $=$ Nano Architecture. Science that works on the molecular scale set to transform the way we build. The biggest changes that led to shaking up architecture in a long time have their origins in the very small Nanotechnology. The understanding and control of matters at a scale of one- to one hundred-billionths of a meter brought incredible changes to the materials and processes of building (Johansen, 2007).

\section{APPLICATIONS OF NANOTECHNOLOGY IN ARCHITECTURE}

- Nanotechnology and Concrete.

Concrete is, after all, a macro-material strongly influenced by its nano-properties and understanding it at this new level is yielding new avenues for improvement of strength (Mann, 2006).

- Nanotechnology and steel.

Advancements in this technology would lead to increased safety, less need for monitoring and more efficient materials use in construction prone to fatigue issues. Current research into the refinement of the cementite phase of steel to a nano-size has produced stronger cables. High strength steel cables, as well as being used in car tyres, are used in bridge construction and in pre-cast concrete tensioning and a stronger cable material would reduce the costs and period of construction, especially in suspension bridges as the cables are run from end to end of the span.

- Nanotechnology and glass.

Most of glass in construction is, on the exterior surface of buildings and the control of light and heat entering through building glazing is a major sustainability issue. Research into nanotechnological solutions to this centers 
around four different strategies to block light and heat coming in through windows. Firstly, thin film coatings are being developed which are spectrally sensitive surface applications for window glass. These have the potential to filter out unwanted infrared frequencies of light (which heat up a room) and reduce the heat gain in buildings, however, these are effectively a passive solution. As an active solution, thermochromic technologies are being studied which react to temperature and provide thermal insulation to give protection from heating whilst maintaining adequate lighting. A third strategy, that produces a similar outcome by a different process, involves photochromic technologies which are being studied to react to changes in light intensity by increasing absorption. And finally, electro chromic coatings are being developed that react to changes in applied voltage by using a tungsten oxide layer.

- Nanotechnology and wood.

Nanotechnology represents a major opportunity for the wood industry to develop new products, substantially reduce processing costs, and open new markets for biobased materials. .(Mann, 2006)

- Nanotechnology and Coatings.

Nanotechnology is being applied to paints and insulating properties, produced by the addition of nano-sized cells, pores and particles, giving very limited paths for thermal conduction ( $\mathrm{R}$ values are double those for insulating foam), are currently available. This type of paint is used, at present, for corrosion protection under insulation since it is hydrophobic and repels water from the metal pipe and can also protect metal from salt water attack.

\section{USING NANOTECHNOLOGY IN ARCHITECTURE}

The prominent American architect John Johansen who studied under Walter Gropius at Harvard School proposes these following projects, which, essence is molecular - growth out of and beyond the confines of the vat. In the early stages of molecular growth processes, small molecules survive only in a sealed vat where an entactic environment is assured.

\section{NANo INitiatives: CASE StUdies}

\section{A. Nano house and studio}

Nano house brings nanotechnology home.

Australia has no formal national nanotechnology initiative, though a series of national networks and programs have been established to bring together relevant research. There is significant government investment in Australian nanotechnology research from the Australian Research Council and the Commonwealth Scientific and Industrial Research Organization as well as funding from state governments. Over 50 Australian companies claim to be working in 'nanotechnology
The Nano House ${ }^{\mathrm{TM}}$ Initiative, by Dr Carl Masens at the Institute for Nano scale Technology and visualized and implemented by architect James Muir, has proven a successful method of explaining what nanotechnologies are and how they work; for example, how the latest technology windows clean themselves, how tiles might resist buildup of soap scum, or timber surfaces resist UV damage. In the building industry, nanotechnology provides a whole new palette of materials that could potentially have profound effects on building design.[Johansen John M. Princeton Architectural Press New York. (2002)]

The NanoHouse has a radioactive cooling paint as the outer surface of some of the roofing material. A metal roof coated with this paint will become a cooling element in a building rather than a source of unwanted heat gain. Other features are self-cleaning glass, cold lighting systems and the dye solar cell - a photovoltaic cell based on titanium dioxide rather than silicon. (Leydecker, 2008).

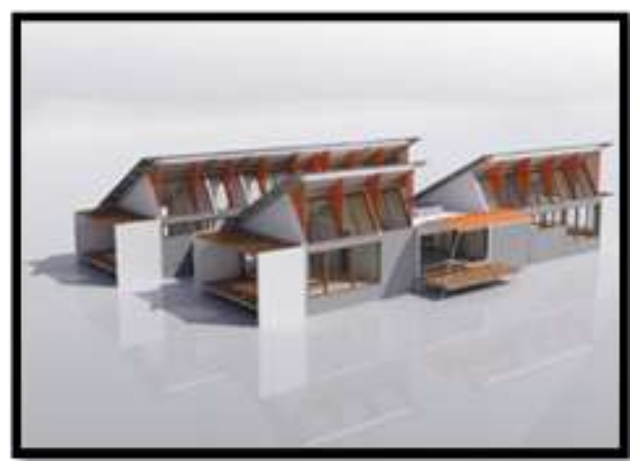

Fig. 1.The white walls of the nanoHOUSE absorbs light and harvests solar energy./ Reference:

http://www.uts.edu.au/research-and-teaching/our-research/nanoscale -technology.

\section{B. Nano studio}

In the Nano Studio, interdisciplinary groups of students from Ball University, and Illinois Institute of Technology are exploring nanotechnology's potential impact on the built environment, as well as social, ethical and environmental issues it raises.

Together they are designing buildings using nanomaterial's including carbon nanotubes, quantum dot displays, and Nano sensors to create new kinds of environments not limited by the constrains of traditional materials. Aware that these radical materials fundamentally after the relationship between buildings, users, and the environment, we are integrating a detailed examination of the social, ethical, and environmental side-effects of nanotechnology into the investigation. The results they hope, will be a proactive contribution to the social discussion on this rapidly developing super technology (Nanostudio. http://daheadley.iweb.bsu.edu/NanoStudio2/.) 


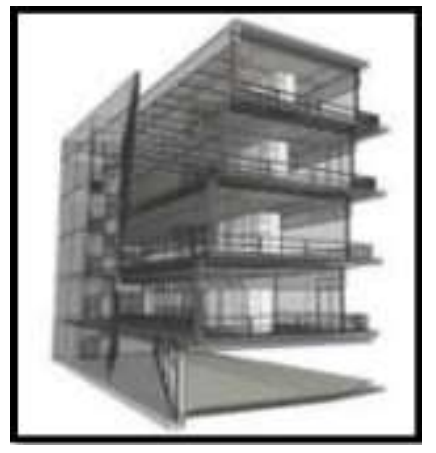

Fig. 2. Using carbon nanotubes in a multistory building (Image courtesy of image Adam Buente + Elizabeth Boone/nanostudio)./

Reference: http://daheadley.iweb.bsu.edu/NanoStudio2/.

\section{Carbon tower}

Architects Peter Testa and Sheila Kennedy have very different practices, but both navigate the uncharted waters of innovative design through collaboration with manufacturers, multidisciplinary interaction, and the adaptation of nascent technologies. "The complexity of contemporary buildings is an enormous achievement, but we need to question how we came to the point of building with such complexity.

We believe we need to rethink how we assemble buildings." These might seem like strange words coming from architect Peter Testa, who, with his partner, Devyn Weiser, has designed a carbon-fiber tower, a complex undertaking that proposes to build a high-rise tower out of composite materials. According to Testa, whose firm, Peter Testa Architects, is located in Santa Monica, California, the willingness to use complex computer modeling tools will allow the design of new buildings, materials, and products that just might transform the building industry.[http://archrecord.construction.com/inTheCause/060 2ArchiFuture/archiFuture.asp]
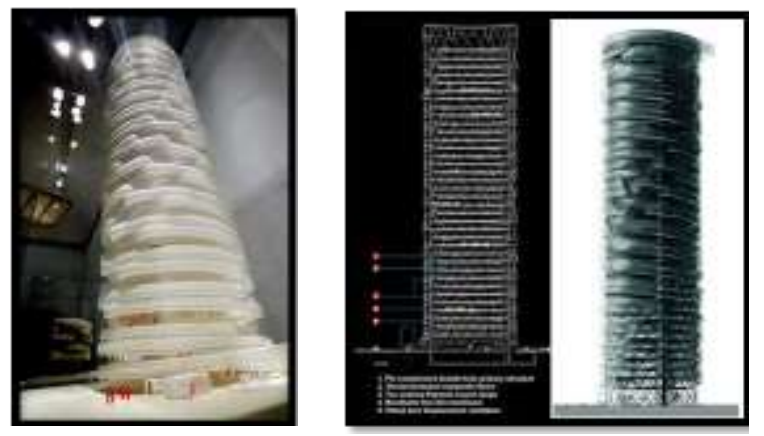

Fig. 3. Perceptional 3D image of the proposed carbon tower \& the longitudinal section of the carbon tower by Peter Testa. Reference: http://archrecord.construction.com/inTheCause/0602ArchiFuture/arc hiFuture.asp.byPeterTesta)

\section{CONCLusion}

The applications of the nanotechnology in architecture can vary widely from early stages of design to the final touches of finishes and throughout the building's lifetime.

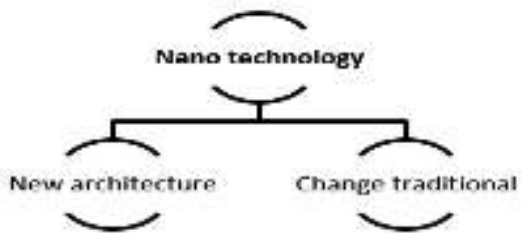

Fig. 4. Disruptive technologies such as nanotechnology give us the opportunity to move into new high value-added areas both. Reference: researcher.

We need architects, scientists and technologies to give careful thought to any ethical, cultural, architectural and environmental issues raised by nanotechnology, to say whether any new regulatory controls are required, and to enter into an open dialogue with the public.

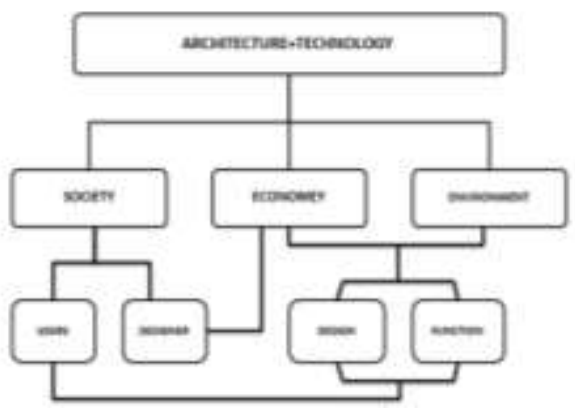

Fig.5. We need architects, scientists and technologies to give careful thought to any Ethical, cultural, architectural and environmental issues raised by Nanotechnology. Reference: researcher.

In conclusion, nanotechnology is disruptive and offers the possibility of great advances whereas conventional approaches, at best, offer only incremental improvements. Nanotechnology is not exactly a new technology, rather it is an extrapolation of current ones to a new scale and at that scale the conventional tools and rules no longer apply. Nanotechnology is therefore the opposite of the traditional top-down process of construction, or indeed any production technique, and it offers the ability to work from the "bottom" of materials design to the "top" of the built environment.

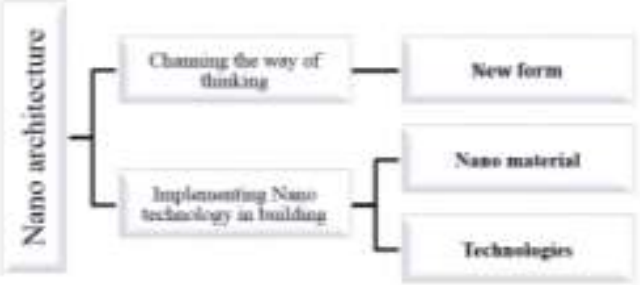

Fig. 6. Nano architecture changing,Reference: researcher.

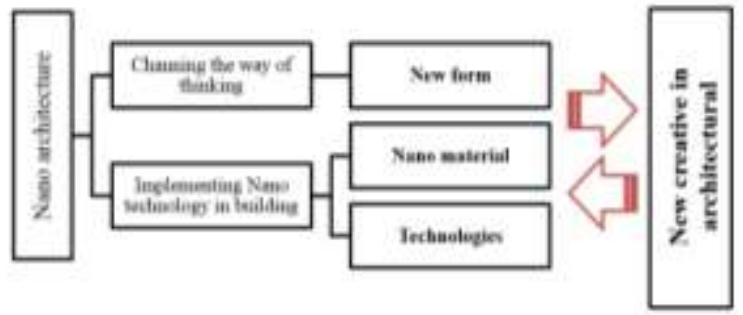

Fig. 7. The New creative in architectural. Reference: researcher. 


\section{REFERENCES}

[1] J. Johansen, M. Princeton, Nano architecture: A New Species of Architecture. Architectural Press New York. (2002).

[2] M. Brayer. Thames \& Hudson, ArchiLab, Migayrou Frederic, 2001.

[3] -Nanohouse. http://www.nano.uts.edu.au/about/australia.html.

[4] -Nanohouse.

http://www.csiro.au/files/mediaRelease/mr2003/Prnanohouse.htm..

[5] Nanotechnology,http://www.referenceworld.com/mosgroup/globalization/n anotechnology.html.

[6] Nanostudio. http://daheadley.iweb.bsu.edu/NanoStudio2/.

[7] http://www.nanotechbuzz.com/50226711/nanostudio_explores_architectur e_and_nanot

[8] echnology.php.

[9] Why the future of architecture does not need us: What becomes of Louis Khan

[10] when buildings actually know what they want to be?. Hosey, Lance.

[11] http://archrecord.construction.com/inTheCause/0602ArchiFuture/archiFut ure.asp.

[12] R. Blaunstein, G. Carpenter. Nanotechnology: The Plastics of the $1^{\text {st }}$ Century, 2006.

[13] British Standard. Nanotechnologies- part 2: Guide to Safe Handling and Disposal of Manufactured Nanomaterials. Published Document, 2007.

[14] F. Simonis, S Schilthuizen, Nanotechnology: Innovation Opportunities for tomorrows Defence, 2006. .

[15] O. Renn, M. Roco, Nanotechnology Risk Governance. International Risk Governance Council,2006.

[16] Irish Council for Science, Technology and Innovation, ICSTI Statement on Nanotechnology, 2004.

[17] Crystal Research Associates. Nanotechnology and the Built Environment: Investing in Green Infrastructure, 2012

[18] S. Mann, Nanotechnology and Construction. European Nanotechnology Gate.2006.

[19] D. Williams Sustainable Design: ECOLOGY, ARCHITECTURE, AND PLANNING, , FAIA (2008)

[20] Nano architecturehttp://sensingarchitecture.com/1347/the-future-of architecture-with-nanotechnology-video/ John M. Johansen interview, 2007.

[21] Faten Fares Fouad, Nano Architecture and Sustainability, Department of Architecture Faculty of Engineering, University of Alexandria, , (2012)

[22] Nanotechnology and Construction, Surinder Mann Institute of Nanotechnology, (2006).

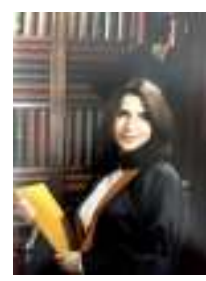

Arch. Leena S. B. Yasin

Lecturer at the College of Engineering / The

University Of Jordan

Kingdom Of Jordan.

Linaryasin@gmail.com

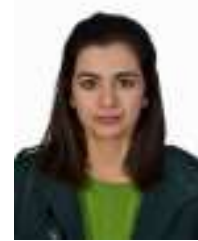

Arch. Diala I Atiyat

Lecturer at the College of Engineering /

AL-Balqaa Applied University.

Kingdom Of Jordan.

Archdiala@yahoo.com 